\title{
Maternal omega-3 supplementation increases fat mass in male and female rat offspring
}

\section{Beverly Sara Muhlhausler ${ }^{1,2 *}$, Dijana Miljkovic ${ }^{1}$, Laura Fong ${ }^{2,3}$, Cory J. Xian ${ }^{2}$, Emmanuelle Duthoit ${ }^{2}$ and Robert A. Gibson'}

1 School of Agriculture Food and Wine, FOODplus Research Centre, The University of Adelaide, Adelaide, SA, Australia

2 School of Pharmacy and Medical Sciences, Sansom Institute for Health Research, University of South Australia, Adelaide, SA, Australia

${ }^{3}$ School of Molecular and Biomedical Science, The University of Adelaide, Adelaide, SA, Australia

Edited by:

Richard D. Emes, University of Nottingham, UK

\section{Reviewed by:}

David S. Gardner, University of Nottingham, UK

Carla Taylor, University of Manitoba,

Canada

\section{*Correspondence:}

Beverly Sara Muhlhausler, FOODplus Research Centre, School of

Agriculture, Food and Wine, The

University of Adelaide, Urrbrae, SA

5064, Australia.

e-mail: beverly.muhlhausler@adelaide. edu.au
Adipogenesis and lipogenesis are highly sensitive to the nutritional environment in utero and in early postnatal life. Omega-3 long chain polyunsaturated fatty acids (LCPUFA) inhibit adipogenesis and lipogenesis in adult rats, however it is not known whether supplementing the maternal diet with omega-3 LCPUFA results in reduced fat deposition in the offspring. Female Albino Wistar rats were fed either a standard chow (Control, $n=10$ ) or chow designed to provide $\sim 15 \mathrm{mg} / \mathrm{kg} /$ day of omega-3 LCPUFA, chiefly as docosahexaenoic acid (DHA), throughout pregnancy and lactation (Omega-3, $n=11$ ) and all pups were weaned onto a commercial rat chow. Blood and tissues were collected from pups at 3 and 6 weeks of age and weights of visceral and subcutaneous fat depots recorded. The expression of adipogenic and lipogenic genes in the subcutaneous and visceral fat depots were determined using quantitative real time reverse transcription-PCR. Birth weight and postnatal growth were not different between groups. At 6 weeks of age, total percentage body fat was significantly increased in both male $(5.09 \pm 0.32 \%$ vs. $4.56 \pm 0.2 \%, P<0.04)$ and female $(5.15 \pm 0.37 \%$ vs. $3.89 \pm 0.36 \%, P<0.04)$ offspring of omega-3 dams compared to controls. The omega-3 LCPUFA content of erythrocyte phospholipids (as a $\%$ of total fatty acids) was higher in omega-3 offspring $(6.7 \pm 0.2 \%$ vs. $5.6 \pm 0.2 \%, P<0.001)$. There was no effect of maternal omega-3 LCPUFA supplementation on the expression of adipogenic or lipogenic genes in the offspring in either the visceral or subcutaneous fat depots. We have therefore established that an omega-3 rich environment during pregnancy and lactation in a rodent model increases fat accumulation in both male and female offspring, particularly in subcutaneous depots, but that this effect is not mediated via upregulation adipogenic/lipogenic gene transcription. These data suggest that maternal $n-3$ LCPUFA supplementation during pregnancy/lactation may not be an effective strategy for reducing fat deposition in the offspring.

Keywords: omega-3, adipose tissue, maternal nutrition

\section{INTRODUCTION}

Obesity is a major public health issue in both industrialized and semi-industrialized nations across the world (World Health Organisation, 2006). Whilst many factors contribute to the development of obesity, there is now evidence that the risk an individual has of becoming obese in later life is related to the nutritional environment they experience before birth and in early infancy (McMillen and Robinson, 2005). A world-wide series of human epidemiological and experimental animal studies in both rodents and large animal models have shown that exposure to an excess supply of energy during critical periods of fetal and infant development is associated with an increased propensity toward excess accumulation of body fat in later life (Plagemann et al., 1997; Armitage et al., 2004; McMillen and Robinson, 2005). In the sheep, exposure to increased glucose concentrations in late fetal life increases the expression of genes within adipose cells which are responsible for promoting lipid storage (Muhlhausler et al., 2007), and this is associated with an increased accumulation of adipose tissue by the end of the first month of life (Muhlhausler et al., 2006). Similarly, in pigs, fat cells which are exposed to high glucose levels before birth have a greater lipogenic capacity in postnatal life (Kasser et al., 1981). Thus, the nutritional environment during the period of fat cell development plays an important role in defining an individual's propensity for accumulating adipose tissue, and therefore their risk of becoming overweight or obese. It has therefore been suggested that increasing the supply of factors which suppress fat accumulation in early life may be effective in reducing body fat mass in child and adult hood (Hauner et al., 2009).

The omega-3 long chain polyunsaturated fatty acids (LCPUFA), docosahexaenoic acid (DHA), and eicosapentaenoic acid (EPA), play an important role in optimal fetal and neonatal development. Whilst most studies to date have focused on their role in neurodevelopment, there has been increasing interest in their potential metabolic effects as a result of data from in vitro studies which have shown that both DHA and EPA can inhibit the 
proliferation and differentiation of pre-adipocytes and selectively inhibit the activity of pro-adipogenic factors (Ailhaud et al., 2006; Massiera et al., 2006). In addition, omega-3 LCPUFA also act on mature adipose cells to inhibit the expression of the key lipogenic mediator sterol-regulated binding protein 1 (SREBP-1c), resulting in a reduced expression of downstream lipogenic genes, including Fatty Acid Synthase (FAS) and glycerol 3-phosphate dehydrogenase $(\mathrm{G} 3 \mathrm{PDH})$ and a reduced accumulation of lipid (Masden et al., 2005). There is therefore good evidence in adult rodents that omega-3 LCPUFAs can reduce the accumulation of body fat by limiting both the hyperplastic and hypertrophic expansion of adipose depots (Okuno et al., 1997; Raclot et al., 1997; Ruzickova et al., 2004).

Despite the evidence linking omega-3 LPCUFA with reduced fat deposition, there have been few studies in either animals or humans which have determined the effect of supplementing the maternal diet with omega-3 LCPUFA on fat deposition in the offspring. The four published human studies which have investigated this have been relatively small with high attrition rates and have, perhaps unsurprisingly given these caveats, produced disparate results (Muhlhausler et al., 2010b). Whilst animal studies have more consistently reported a reduction in fat mass in offspring of mothers receiving a diet supplemented with omega-3 LCPUFA during pregnancy and/or lactation (Korotkova et al., 2002; Massiera et al., 2003; Wyrwoll et al., 2006; Ibrahim et al., 2009), all but one of these studies have also weaned the offspring onto a high omega-3 LCPUFA diet. Therefore, it remains unclear whether exposure to an increased supply of omega-3 LCPUFA during the perinatal period alone is associated with reduced fat mass in the offspring after weaning.

The aim of the current study was to determine the effect of supplementing the diet of rat dams with omega-3 LCPUFA during pregnancy and lactation on postnatal growth, fat mass and the expression of adipogenic and lipogenic genes in the major visceral and subcutaneous fat depots in offspring supplied with a standard rodent chow diet with no omega-3 LCPUFA supplementation after weaning.

\section{MATERIALS AND METHODS ANIMALS AND DIETS}

This study was approved by the Animal Ethics Committee of the Institute of Medical and Veterinary Science, Central Northern Adelaide Health Services, South Australia. Twenty-one female and eight male Albino Wistar rats (200-250 g) were individually housed under a $12 \mathrm{~h} \mathrm{light} / 12 \mathrm{~h}$ dark cycle at a room temperature of $25^{\circ} \mathrm{C}$. Female rats were fed ad libitum on a rat chow which was designed to have a fatty acid composition which was similar to the standard Australian diet (40\% saturates, $40 \%$ monounsaturates, 20\% polyunsaturates; Meyer et al., 2003; Specialty Feeds, Glen Forrest, WA, Australia) for at least 3 weeks prior to mating in order to ensure that the fatty acid profile of all animals was comparable prior to the dietary intervention. After 3 weeks on the diet, blood samples were collected to determine fatty acid status. Female rats were then mated and randomly assigned to receive the same diet (5\% fat, $0.22 \% n-3$ LCPUFA of total fatty acids, Control, $n=10$ ) or a high omega-3 diet (5\% fat, $1.29 \% n-3$ LCPUFA of total fatty acids, Omega- $3, n=11$ ) throughout pregnancy and lactation. The high omega-3 diet was designed to provide a dose of between 6.5 and $9.0 \mathrm{mg} n-3$ LCPUFA/day $(\sim 15 \mathrm{mg} / \mathrm{kg} /$ day $)$ which was equivalent to the dose provided to women in the largest randomized controlled trial of maternal omega-3 supplementation in pregnancy (Makrides et al., 2010). Both diets were isocaloric and contained 20\% protein, $59 \%$ carbohydrate, and $5 \%$ fat by weight, such that the only significant difference between the diets was in the fatty acid composition, chiefly the omega3 LCPUFA content. The fatty acid composition of the Control and Omega-3 diets is shown in Table 1. Food intake was determined in all dams every 2 days during pregnancy and lactation, and fresh food provided. Dams were weighed weekly during pregnancy and lactation.

Dams were allowed to give birth naturally at term and birth weight and litter size was recorded. All pups remained with their natural mothers during the suckling period. Offspring from both the Control and Omega-3 groups were weaned onto the same commercial rat chow (Rat and Mouse cubes, Specialty Feeds, Glen Forrest, WA, Australia) at 21 days of age, which ensured that the only time when pups in the respective treatment groups were exposed to different fatty acid environments was during the fetal and suckling periods. The commercial rat feed contained $20 \%$ protein, $59.4 \%$ carbohydrate, and $4.8 \%$ fat by weight. The EPA and DHA content of the feed (expressed as a percentage of total fatty acids) was 0.02 and $0.05 \%$ respectively, and no additional omega-3 LCPUFA were added to the diet. The pups were weighed every 2 days from birth to weaning and once a week thereafter until the end of the experiment.

\section{BLOOD SAMPLE AND TISSUE COLLECTION}

Blood and tissues were collected in the non-fasting state from the dam at the end of lactation and one male and one female pup from each litter at 3 weeks (weaning) and 6 weeks of age. All animals were euthanized with an overdose of $\mathrm{CO}_{2}$. Body weight was recorded immediately before euthanasia in all animals. After euthanasia, the length of all rats was measured from the tip of the nose to the base of the tail. The abdominal circumference was measured at the largest point of the abdomen. Both of these measurements were carried out by the same investigator using a flexible twine which was subsequently measured to the nearest millimeter using the same ruler. All adipose tissue depots including

Table 1 | Fatty acid composition of the Control and Omega-3 diets (values expressed as $\%$ total fatty acids); both diets contain $5 \%$ fat $(v / v)$.

\begin{tabular}{lccl}
\hline Fatty acid & $\begin{array}{l}\text { Standard diet } \\
(\mathbf{1 . 5 \%} \boldsymbol{n} \mathbf{- 3})\end{array}$ & $\begin{array}{l}\text { High DHA diet } \\
\mathbf{( 3 . 3 \%} \boldsymbol{n} \mathbf{- 3})\end{array}$ & $\boldsymbol{P}$ value \\
\hline Total saturates & $43.34 \pm 0.09$ & $42.76 \pm 0.09$ & $<0.05$ \\
$16: 1 n-7$ & $2.66 \pm 0.008$ & $2.62 \pm 0.004$ & $\mathrm{~ns}$ \\
$18: 1 n-9$ & $33.26 \pm 0.17$ & $33.21 \pm 0.07$ & $\mathrm{~ns}$ \\
$18: 2 n-6(\mathrm{LA})$ & $11.93 \pm 0.058$ & $11.91 \pm 0.10$ & $\mathrm{~ns}$ \\
$18: 3 n-3(\mathrm{ALA})$ & $1.20 \pm 0.002$ & $1.21 \pm 0.005$ & $\mathrm{~ns}$ \\
$20: 5 n-3(\mathrm{EPA})$ & $0.14 \pm 0.002$ & $0.34 \pm 0.005$ & $<0.01$ \\
$22: 2 n-6$ & $0.027 \pm 0.003$ & $0.025 \pm 0.0003$ & $\mathrm{~ns}$ \\
$22: 6 n-3(\mathrm{DHA})$ & $0.08 \pm 0.005$ & $0.95 \pm 0.002$ & $<0.001$
\end{tabular}


the retroperitoneal, gonadal, omental, interscapular, and subcutaneous, were dissected out and weighed. The mass of all adipose depots were added to obtain a measure of total body fat mass. At 6 weeks of age, a sample from the retroperitoneal and subcutaneous adipose depot was snap frozen in liquid nitrogen and stored at $-80^{\circ} \mathrm{C}$ for subsequent determination of gene expression by quantitative real time reverse transcription-PCR (qRT-PCR). Blood samples were collected by cardiac puncture. The blood was centrifuged at $3500 \mathrm{rpm}(800 \mathrm{~g}), 4^{\circ} \mathrm{C}$ for $15 \mathrm{~min}$. The plasma was removed and stored at $-20^{\circ} \mathrm{C}$ for subsequent analyses of glucose, insulin, and non-esterified free fatty acids (NEFA) concentrations. The remaining red blood cell mass was then prepared for fatty acid analysis of red blood cell phospholipids as previously described (Makrides et al., 1995).

\section{LIPID EXTRACTION}

All solvents used in this study were analytical grade and were purchased from Ajax Finechem Pty Ltd (Auckland, New Zealand) or Chem-Supply (SA, Australia). Other chemicals and reagents were purchased from Sigma-Aldrich (St. Louis, MO, USA) unless specified otherwise. The total lipid concentration of the plasma was determined following the protocol of Bligh and Dyer (1959) using chloroform-methanol $(2: 1, \mathrm{v} / \mathrm{v})$. The phospholipids were separated from total lipid extracts by thin layer chromatography (TLC) on silica gel plates (Silica gel 60H; Merck, Darmstadt, Germany). A lipid class standard 18-5 (NU-CHEK Prep; Elysian, MN, USA) was run on the plates for lipid identification. The mobile phase for TLC was petroleum spirit/acetone $(3: 1, v / v)$. The TLC plates were sprayed with fluorescein 5 -isothiocyanate in methanol, and the lipid classes present were visualized under UV light. The phospholipid bands located at the bottom of TLC plate were transferred into a vial containing $1 \%$ sulphuric acid $\left(\mathrm{H}_{2} \mathrm{SO}_{4}\right)$ in methanol. All solvents used for extraction and separation contained $0.005 \%(\mathrm{w} / \mathrm{v})$ of the antioxidant, butylated hydroxyl toluene (BHT).

\section{FATTY ACID METHYLATION AND GAS CHROMATOGRAPHIC ANALYSIS OF FAME}

All lipids and phospholipids were transesterified with $1 \% \mathrm{H}_{2} \mathrm{SO}_{4}$ in methanol at $70^{\circ} \mathrm{C}$ for $3 \mathrm{~h}$. After the samples were cooled, the resulting fatty acid methyl esters (FAME) were extracted with $n$ heptane and transferred into vials containing a scoop of anhydrous sodium sulfate $\left(\mathrm{Na}_{2} \mathrm{SO}_{4}\right)$.

Fatty acid methyl esters were separated and quantified by gas chromatography (GC) (Hewlett-Packard 6890; Palo Alto, CA, USA) equipped with a capillary column $(50 \mathrm{~m} \times 0.32 \mathrm{~mm}$ id $)$ coated with $0.25 \mu \mathrm{m}$ film thickness silica (BPX-70; SGC Pty Ltd, VIC, Australia), and a flame ionization detector (FID). The injector temperature was set at $250^{\circ} \mathrm{C}$ and the FID temperature at $300^{\circ} \mathrm{C}$. The oven temperature at injection was initially set at $140^{\circ} \mathrm{C}$ and was programmed to increase to $220^{\circ} \mathrm{C}$ at a rate of $5^{\circ} \mathrm{C} / \mathrm{min}$. Helium gas was utilized as a carrier at a flow rate of $35 \mathrm{~cm} / \mathrm{s}$ in the column. The identification and quantification of FAMEs were achieved by comparing the retention times and peak area\% values of unknown samples to those of commercial lipid standards (NU-CHEK Prep; Elysian, MN, USA) using the Hewlett-Packard Chemstation data system. FAME standards for unique $n-3$ LCPUFAs $24: 5 n-3$ and 24:6n-3 were purchased from Larodan Fine Chemicals (Malmö, Sweden).

\section{DETERMINATION OF HORMONE AND METABOLITE CONCENTRATIONS}

Plasma concentrations of non-esterified fatty acids (NEFA) and glucose were determined using Wako NEFA C kit (Wako Pure Chemical Industries Ltd, Osaka, Japan) and Infinity Glucose Hexokinase kit (Thermo Electron, Pittsburgh, PA, USA) respectively. Assays and analyses were conducted using Konelab 20 (Thermo Scientific, Vantaa, Finland) and the coefficient of variation for both assays was $<5 \%$. Insulin concentrations were measured by radioimmunoassay with a Linco Rat Insulin Kit (Linco Research, St. Charles, MO, USA). The inter- and intra-assay coefficients of variation were both $<10 \%$.

\section{ISOLATION OF RNA FROM ADIPOSE TISSUE AND REVERSE TRANSCRIPTION}

RNA was isolated from $\sim 100 \mathrm{mg}$ retroperitoneal and subcutaneous adipose tissue from 6 week male and female offspring using Trizol reagent (Invitrogen Australia Pty Limited, Australia) and chloroform. The RNA was purified using the RNeasy Mini Kit (QIAGEN Pty Ltd-Australia, Doncaster, Australia). The purity and concentration of RNA were determined using a spectrophotometer measuring absorbance at 260 and $280 \mathrm{~nm}$ and the integrity of the RNA was determined using agarose gel electrophoresis. cDNA was then synthesized using the purified RNA $(\sim 2 \mu \mathrm{g})$, Superscript III Reverse Transcriptase (Invitrogen Australia Pty Limited, Australia) and random hexamers.

\section{QUANTITATIVE REAL TIME REVERSE TRANSCRIPTION-PCR}

Quantitative real time PCR was conducted using SYBR Green in an ABI Prism 7300 Sequence Detection System (PE Applied Biosystems, Foster City, CA, USA). The expression of sterol regulatory element-binding protein 1 (SREBP1), fatty acid synthase (FAS), glycerol 3-phosphate dehydrogenase (G3PDH), peroxisome proliferator-activated receptor gamma (PPAR $\gamma)$, leptin, and $\beta$-actin was determined by qRT-PCR. The primers for all genes have been previously validated and published (Muhlhausler et al., 2010a). The $\beta$-actin primer set was purchased from Qiagen Pty Ltd. (Doncaster, Australia). Each PCR reaction contained $5 \mu \mathrm{l}$ $2 \times$ SYBR Green master mix (PE Applied Biosystems, Foster City, CA, USA), $1 \mu \mathrm{l}$ each of forward and reverse primers at a concentration of $60-900 \mathrm{nM}, 2 \mu \mathrm{l}$ of molecular grade water and $1 \mu \mathrm{l}$ of $50 \mathrm{ng} / \mu \mathrm{l}$ dilution of cDNA stock template. Each reaction was conducted in triplicate. Cycling conditions include 40 cycles of $95^{\circ} \mathrm{C}$ for $1 \mathrm{~min}$ and $60^{\circ} \mathrm{C}$ for $1 \mathrm{~min}$. At the end of each run, melt curve analysis was performed to verify amplification of a single product. A quality control sample was included on each plate in order to confirm consistency of results between individual runs, and the inter-plate coefficient of variation was $<5 \%$.

The abundance of each mRNA transcript was measured and expression relative to that of $\beta$-actin was calculated using Q-gene qRT-PCR analysis software. This software provides a quantitative measure of the relative abundance of a specific transcript in different tissues by the comparative threshold cycle $\left(\mathrm{C}_{t}\right)$ method which takes into account any differences in the amplification efficiencies of the target and reference genes. The $C_{t}$ value was taken as the lowest statistically significant (>10 SD increase in fluorescence above the background signal in an amplification reaction. 


\section{STATISTICAL ANALYSIS}

Data are presented as mean \pm SEM. The effect of maternal omega3 supplementation during pregnancy and lactation on maternal body weight at the end of lactation, maternal body fat mass and maternal fatty acid, hormone, and metabolite concentrations was analyzed by Student's unpaired $t$-test. The effect of maternal omega-3 supplementation on birth outcomes and fatty acid composition of erythrocytes in 3- and 6-week offspring were similarly examined. The effect of maternal omega-3 supplementation on maternal weight change during pregnancy and lactation, and postnatal weight gain in male and female offspring was determined using an ANOVA with repeated measures. The effect of maternal omega-3 supplementation and pup sex on hormone and metabolite concentrations, body fat mass, and adipocyte genes in the offspring was determined using a two-way ANOVA. Where the ANOVA identified a significant interaction between sex and maternal treatment, the effect of omega-3 supplementation was analyzed separately in male and female offspring. Litter size was included as a covariate in all analyses, and only one pup from each litter was included for each measurement and time-point. All data were tested to confirm normality of distribution and relationships between variables were assessed using simple linear regression. A $P$ value of $<0.05$ was considered to be statistically significant in all analyses.

\section{RESULTS \\ THE EFFECT OF MATERNAL OMEGA-3 SUPPLEMENTATION ON MATERNAL CHARACTERISTICS DURING PREGNANCY AND LACTATION}

There was no difference in omega-3 LCPUFA content of maternal erythrocytes of rats assigned to the control and omega-3 DHA groups prior to being fed the experimental diets (Control, $6.01 \pm 0.09 \%$; Omega-3, $6.40 \pm 0.33 \%$ ). At the end of lactation, DHA, EPA, and total omega-3 LCPUFA contents of maternal erythrocytes were significantly higher in the omega-3 supplemented dams compared to Controls (Table 2). There was no effect of maternal omega-3 supplementation on omega- 6 fatty acid concentrations (Table 2).

Table 2 | Maternal erythrocyte phospholipid fatty acid composition expressed as a percentage of total fatty acids and glucose, insulin, and NEFA concentrations at the end of lactation in Control and Omega-3 dams.

\begin{tabular}{lccc}
\hline & Control $(\boldsymbol{n}=\mathbf{1 0})$ & Omega-3 $(\boldsymbol{n}=\mathbf{1 1})$ & $\boldsymbol{P}$ value \\
\hline EPA (\%) & $0.54 \pm 0.04$ & $0.67 \pm 0.03$ & 0.03 \\
DHA (\%) & $2.30 \pm 0.11$ & $3.68 \pm 0.22$ & $<0.001$ \\
Total $n-3$ LCPUFA (\%) & $3.81 \pm 0.09$ & $5.42 \pm 0.26$ & $<0.001$ \\
LA (\%) & $7.49 \pm 0.31$ & $6.92 \pm 0.24$ & $\mathrm{~ns}$ \\
AA (\%) & $19.654 \pm 0.61$ & $18.44 \pm 0.87$ & $\mathrm{~ns}$ \\
Glucose (mmol/l) & $3.58 \pm 0.28$ & $3.31 \pm 0.23$ & $\mathrm{~ns}$ \\
Insulin (ng/ml) & $1.12 \pm 0.19$ & $1.10 \pm 0.16$ & $\mathrm{~ns}$ \\
NEFA (mEq/l) & $0.82 \pm 0.17$ & $0.55 \pm 0.11$ & 0.03 \\
& & & \multicolumn{2}{c}{0.03}
\end{tabular}

All values expressed as mean $\pm S E M$. Differences between the Omega-3 and Control groups were determined using a Student's unpaired t-test. $P<0.05$ was considered statistically significant.
There was no difference in the weight of the mothers before mating (i.e., prior to allocation to the Control or Omega-3 diet; Control, $327.4 \pm 16.7 \mathrm{~g}$; Omega-3, $335.7 \pm 10.6 \mathrm{~g}$ ). There was no effect of maternal omega-3 supplementation on maternal weight gain during pregnancy (Control, 106.7 $\pm 10.4 \mathrm{~g}$; Omega-3, 103.5 $\pm 14.9 \mathrm{~g}$ ) or weight loss after delivery (Control, $-75.5 \pm 9.6 \mathrm{~g}$; Omega- $3,-79.7 \pm 12.0 \mathrm{~g}$ ), and there was no difference in maternal body weight at the end of lactation between the Control and Omega-3 groups (Control, 340.6 $\pm 10.9 \mathrm{~g}$; Omega-3, $354.1 \pm 4.9 \mathrm{~g})$.

At the end of lactation, the Omega- 3 dams had a higher total subcutaneous fat mass (Control, $1.06 \pm 0.18 \mathrm{~g}$; Omega-3, $3.12 \pm 0.84 \mathrm{~g}, P<0.05)$ and also tended $(P<0.06)$ to have a higher subcutaneous fat mass as a percentage of body weight (Control, $0.31 \pm 0.05 \%$; Omega-3, $0.89 \pm 0.02 \%$ ). There was no difference, however, in the total or relative weight of any other major fat depots or total percentage body fat (percent body fat mass: Control, $4.8 \pm 0.4 \%$; Omega- $3,5.4 \pm 0.4 \%)$.

There was no difference in maternal glucose or insulin levels between the Control and Omega-3 dams; however plasma NEFA concentrations at the end of lactation were lower in Omega- 3 dams (Table 2). Maternal omega-3 intake had no effect on food intake during either pregnancy (Control, $10.62 \pm 1.92 \mathrm{~g} /$ day; Omega$3,14.94 \pm 4.8 \mathrm{~g} /$ day) or lactation (Control, $15.78 \pm 4.89 \mathrm{~g} /$ day; Omega-3, $12.5 \pm 3.6 \mathrm{~g} /$ day).

\section{PREGNANCY AND BIRTH OUTCOMES}

There was no effect of maternal omega-3 supplementation on length of gestation (Control, 22.3 \pm 0.5 days; Omega-3, $23.3 \pm 0.6$ days), litter size (Control, $9.1 \pm 1.4$ pups; Omega-3, $6.7 \pm 0.8$ pups) or mean pup birth weight (Control, $6.27 \pm 0.24$ g; Omega-3, $6.94 \pm 0.41 \mathrm{~g})$. There were equal number of litters with dead pups in each treatment group (Control, $n=2$ litters, DHA, $n=3$ litters), and there was an average of two dead pups in each of these litters. All pups that were not dead at birth survived until weaning.

\section{THE EFFECT OF MATERNAL OMEGA-3 SUPPLEMENTATION ON OFFSPRING CHARACTERISTICS: FATTY ACID STATUS AND HORMONE AND METABOLITE CONCENTRATIONS}

The offspring of omega-3 supplemented dams had significantly higher concentrations of DHA, EPA, and total omega-3 LCPUFA in their erythrocyte phospholipids at both 3 and 6 weeks of age (Table 3).

There was no effect of maternal omega- 3 supplementation or offspring sex on plasma insulin concentrations at either 3 or 6 weeks of age (Table 4). There was also no effect of maternal omega-3 supplementation on glucose concentrations at 3 weeks of age in either male or female offspring; however at 6 weeks of age, plasma glucose concentrations were lower in female Omega3 offspring compared to their Control counterparts (Table 4). There was no effect of maternal omega-3 supplementation on plasma glucose concentrations in 6 week male offspring (Table 4). At 3 weeks, but not 6 weeks, of age, plasma NEFA concentrations were lower in Omega-3 offspring compared to Control offspring in both males and females (Table 4). 
Table 3 | Erythrocyte phospholipid fatty acid composition expressed as a percentage of total fatty acids at 3 and 6 weeks of age in offspring of Control and Omega-3 dams.

\begin{tabular}{lccl}
\hline 3 Week offspring & Control $(\boldsymbol{n}=\mathbf{1 4})$ & Omega-3 $(\boldsymbol{n}=\mathbf{1 8})$ & $\boldsymbol{P}$ value \\
\hline EPA (\%) & $0.32 \pm 0.03$ & $0.39 \pm 0.02$ & 0.05 \\
DHA (\%) & $4.53 \pm 0.27$ & $7.08 \pm 0.21$ & $<0.001$ \\
Total $n-3$ LCPUFA (\%) & $6.67 \pm 0.33$ & $9.39 \pm 0.28$ & $<0.001$ \\
LA (\%) & $7.16 \pm 0.88$ & $6.50 \pm 0.08$ & $\mathrm{~ns}$ \\
AA (\%) & $19.54 \pm 0.31$ & $18.73 \pm 0.37$ & $\mathrm{~ns}$ \\
\hline 6Week offspring & Control $(\boldsymbol{n}=\mathbf{1 4})$ & Omega-3 $(\boldsymbol{n}=\mathbf{1 6})$ & $\boldsymbol{P}$ value \\
\hline EPA (\%) & $0.28 \pm 0.04$ & $0.43 \pm 0.02$ & $<0.001$ \\
DHA (\%) & $3.19 \pm 0.12$ & $4.08 \pm 0.11$ & $<0.001$ \\
Total $n-3$ LCPUFA (\%) & $4.87 \pm 0.28$ & $6.49 \pm 0.13$ & $<0.001$ \\
LA (\%) & $8.57 \pm 0.30$ & $8.94 \pm 0.22$ & $\mathrm{~ns}$ \\
AA (\%) & $17.73 \pm 0.54$ & $18.85 \pm 0.32$ & $\mathrm{~ns}$ \\
\hline
\end{tabular}

All values expressed as mean \pm SEM. Differences between the Omega-3 and Control groups were determined using a Student's unpaired t-test. $P<0.05$ was considered statistically significant.

Table 4 | Plasma glucose, insulin, and NEFA concentrations at 3 and 6 weeks of age in offspring of Control and Omega-3 dams.

\begin{tabular}{|c|c|c|c|c|}
\hline \multirow[b]{2}{*}{$\begin{array}{l}3 \text { Week } \\
\text { offspring }\end{array}$} & \multicolumn{2}{|c|}{ Male } & \multicolumn{2}{|c|}{ Female } \\
\hline & $\begin{array}{l}\text { Control } \\
(n=7)\end{array}$ & $\begin{array}{l}\text { Omega-3 } \\
(n=9)\end{array}$ & $\begin{array}{l}\text { Control } \\
(n=7)\end{array}$ & $\begin{array}{l}\text { Omega-3 } \\
(n=9)\end{array}$ \\
\hline Glucose (mmol/l) & $4.12 \pm 0.19$ & $3.36 \pm 0.17$ & $3.66 \pm 0.28$ & $3.65 \pm 0.17$ \\
\hline Insulin (ng/ml) & $0.57 \pm 0.06$ & $0.95 \pm 0.20$ & $0.75 \pm 0.18$ & $1.10 \pm 0.16$ \\
\hline NEFA (mEq/l) & $0.61 \pm 0.06$ & $0.43 \pm 0.04^{*}$ & $0.57 \pm 0.08$ & $0.49 \pm 0.06^{*}$ \\
\hline $\begin{array}{l}6 \text { Week } \\
\text { offspring }\end{array}$ & $\begin{array}{l}\text { Control } \\
(n=9)\end{array}$ & $\begin{array}{l}\text { Omega-3 } \\
(n=8)\end{array}$ & $\begin{array}{l}\text { Control } \\
(n=9)\end{array}$ & $\begin{array}{l}\text { Omega-3 } \\
(n=9)\end{array}$ \\
\hline Glucose $(\mathrm{mmol} / \mathrm{l})$ & $3.69 \pm 0.39$ & $4.03 \pm 0.38$ & $3.42 \pm 0.24$ & $2.71 \pm 0.10^{*}$ \\
\hline Insulin (ng/ml) & $1.49 \pm 0.15$ & $1.80 \pm 0.47$ & $1.58 \pm 0.29$ & $1.38 \pm 0.16$ \\
\hline NEFA (mEq/l) & $0.53 \pm 0.10$ & $0.41 \pm 0.07$ & $0.44 \pm 0.09$ & $0.58 \pm 0.21$ \\
\hline
\end{tabular}

All values expressed as mean \pm SEM. The effect of Omega-3 treatment and sex was determined using a two-way ANOVA. Where the ANOVA revealed a significant interaction between treatment and sex, differences between the Control and Omega-3 groups were analyzed separately in male and female offspring using a Students' unpaired t-test. ${ }^{*}$ denotes $P<0.05$ compared to Control offspring.

\section{POSTNATAL GROWTH}

There was no effect of maternal omega-3 supplementation on weight gain of the pups between birth and weaning (Figure 1). There was no effect of maternal omega- 3 supplementation on weight gain between weaning and 6 weeks of age in either males or females (Male: Control, $144.4 \pm 8.8 \mathrm{~g}$; Omega-3, $138.2 \pm 9.9 \mathrm{~g}$; Female: Control, $106.8 \pm 7.9 \mathrm{~g}$; Omega-3, $98.0 \pm 4.8 \mathrm{~g})$. Body weight, length, and abdominal circumference at weaning ( 3 weeks of age) and 6 weeks were not different between the control and Omega-3 offspring in either males or females (Table 5).

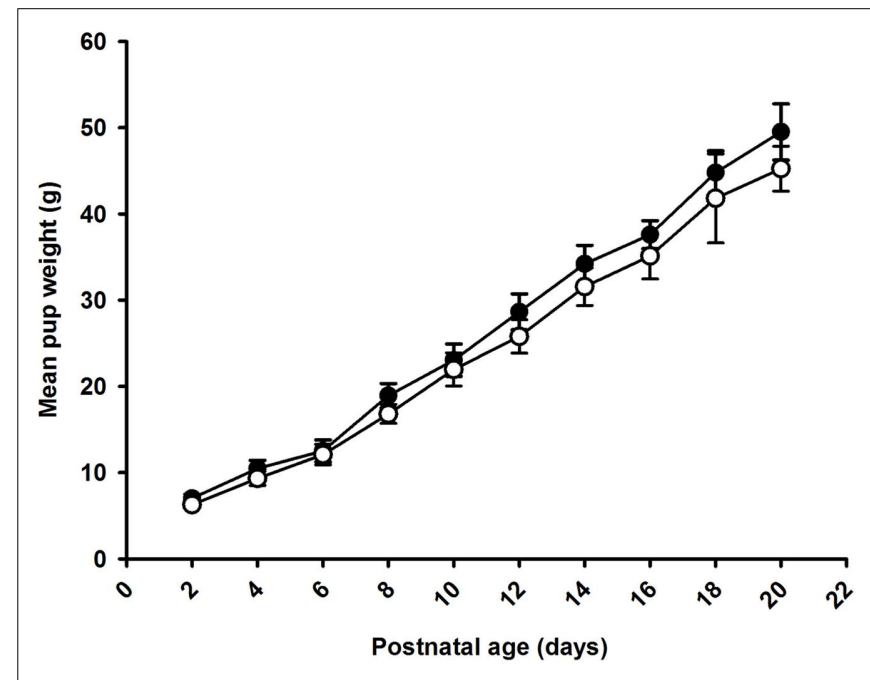

FIGURE 1 | Weight gain from birth to weaning in Control (open circles) and Omega-3 (closed circles) offspring. The effect of Omega-3 treatment on weight gain from birth to weaning was assessed by a one-way ANOVA with repeated measures. Data from male and female offspring combined. There was no effect of maternal omega-3 supplementation on weight gain of the offspring from birth until weaning.

\section{BODY COMPOSITION}

There was no effect of maternal omega-3 supplementation on the total or relative weight of any of the major visceral or subcutaneous fat depots at 3 weeks of age in either male or female offspring (Table 5).

At 6 weeks of age, total percentage body fat was higher in Omega-3 offspring compared to Controls independent of sex $(F=6.18, P<0.01$, Figure $2 \mathrm{~A})$. This appeared to be the result of an increased accumulation of subcutaneous adipose tissue; the subcutaneous fat mass as a percentage of body weight was greater in male and female Omega-3 offspring compared to Controls $(F=5.62, P<0.03$; Figure 2B), but there was no effect of maternal omega-3 supplementation on the relative weight of the major visceral fat depots, the omental, retroperitoneal, interscapular or gonadal fat depots (Table 5).

\section{EXPRESSION OF ADIPOGENIC AND LIPOGENIC GENES IN VISCERAL AND SUBCUTANEOUS ADIPOSE TISSUE IN OFFSPRING AT 6 WEEKS OF AGE}

There was no effect of maternal omega-3 supplementation on the expression of PPAR $\gamma$, FAS, SREBP-1c, G3PDH, or leptin mRNA in retroperitoneal or subcutaneous adipose tissue in either male or female offspring (Table 6). FAS mRNA expression in retroperitoneal adipose tissue tended $(P=0.06)$ to be reduced in the omega-3 female offspring compared to Controls.

When data from Omega-3 and Control offspring were combined, there was a positive relationship between SREBP-1c mRNA expression in retroperitoneal adipose tissue and erythrocyte EPA concentrations in the offspring $(r=0.45, P<0.05)$. There were no relationships, however, between the expression of any adipogenesis and lipogenesis-related genes and either DHA or total omega-3 LCPUFA content of erythrocytes. 
Table 5 | Pup body weight, size, and percentage fat mass at 3 and 6 weeks of age in offspring of Control and Omega-3 dams.

\begin{tabular}{|c|c|c|c|c|}
\hline \multirow[b]{2}{*}{3 Week offspring } & \multicolumn{2}{|c|}{ Male } & \multicolumn{2}{|c|}{ Female } \\
\hline & Control $(n=10)$ & Omega-3 $(n=11)$ & Control $(n=10)$ & Omega-3 $(n=11)$ \\
\hline Body length (cm) & $14.13 \pm 0.45$ & $14.21 \pm 0.30$ & $13.47 \pm 0.39$ & $13.9 \pm 0.30$ \\
\hline Abdominal circumference $(\mathrm{cm})$ & $10.25 \pm 0.30$ & $11.17 \pm 0.39$ & $10.43 \pm 0.42$ & $10.94 \pm 0.44$ \\
\hline Gonadal fat mass $(\%)$ & $1.73 \pm 0.29$ & $1.61 \pm 0.29$ & $1.67 \pm 0.38$ & $1.70 \pm 0.36$ \\
\hline Omental fat mass $(\%)$ & $0.56 \pm 0.60$ & $0.52 \pm 0.03$ & $0.55 \pm 0.03$ & $0.52 \pm 0.04$ \\
\hline Interscapular fat mass (\%) & $0.96 \pm 0.12$ & $0.83 \pm 0.06$ & $0.99 \pm 0.12$ & $0.89 \pm 0.15$ \\
\hline Subcutaneous fat mass (\%) & $2.63 \pm 0.25$ & $2.91 \pm 0.65$ & $2.71 \pm 0.24$ & $3.16 \pm 0.42$ \\
\hline Total fat mass $(\%)$ & $6.81 \pm 0.66$ & $6.66 \pm 0.98$ & $5.30 \pm 0.11$ & $6.70 \pm 0.83$ \\
\hline 6 Week offspring & Control $(n=10)$ & Omega-3 $(n=10)$ & Control $(n=10)$ & Omega-3 $(n=10)$ \\
\hline Interscapular fat mass (\%) & $0.33 \pm 0.02$ & $0.38 \pm 0.08$ & $0.39 \pm 0.05$ & $0.52 \pm 0.06$ \\
\hline Gonadal fat mass $(\%)$ & $1.63 \pm 0.13$ & $1.40 \pm 0.10$ & $1.04 \pm 0.20$ & $1.50 \pm 0.21$ \\
\hline Retroperitoneal fat mass (\%) & $0.77 \pm 0.11$ & $0.80 \pm 0.11$ & $0.58 \pm 0.06$ & $0.73 \pm 0.03$ \\
\hline Omental fat mass $(\%)$ & $0.58 \pm 0.04$ & $0.56 \pm 0.03$ & $0.59 \pm 0.04$ & $0.59 \pm 0.03$ \\
\hline
\end{tabular}

All values expressed as mean \pm SEM. The effect of Omega-3 treatment and sex was determined using a two-way ANOVA.

\section{DISCUSSION}

We have shown that maternal omega-3 supplementation during pregnancy and lactation was without effect on body weight or fat mass of offspring at weaning, and was associated with a significant increase in percentage body fat at 6 weeks of age in both males and females when offspring were weaned onto a standard rat feed which was not supplemented with omega-3 LCPUFA. This increase in fat mass appeared to be restricted to subcutaneous depots, and there was no effect of maternal omega-3 supplementation on the relative mass of visceral fat, suggesting a differential susceptibility of distinct fat depots to the effects of perinatal omega-3 LCPUFA supplementation. Interestingly, there was no effect of maternal omega-3 supplementation on the expression of any of the key adipogenic or lipogenic genes in the subcutaneous depot, suggesting that the increased lipid accumulation is likely to be driven by a mechanism other than the upregulation of lipogenic gene transcription.

\section{OMEGA-3 SUPPLEMENTATION DID NOT ADVERSELY AFFECT PREGNANCY OUTCOME}

We found that maternal omega-3 supplementation during pregnancy, at a dose equivalent to that used in human studies (Makrides et al., 2010), did not affect maternal body weight during pregnancy or lactation. The increased subcutaneous fat mass and lower plasma NEFA concentrations at the end of lactation in dams supplemented with omega-3 LCPUFA, however, suggest that the increased intake of omega-3 LPCUFA resulted either in an increased fat deposition or reduced mobilization of body fat stores during pregnancy. There was a decline in omega-3 LCPUFA content of maternal erythrocytes during pregnancy and lactation in the control group, which implies that the control diet was unable to meet the omega-3 LCPUFA requirements of pregnancy and lactation, and that it was necessary for the Control dams to mobilize maternal fat stores in order to meet their increased omega-3 LCPUFA requirements. The decline in omega-3 LCPUFA content was blunted in the omega- 3 dams, suggesting that requirements were met to a large extent by the maternal diet. It is also possible that the increased intake of omega- 3 fatty acids attenuated the decrease in insulin sensitivity in peripheral tissues, including adipose tissue, which is normally associated with pregnancy, since previous studies have reported that increased intake of omega-3 fatty acids is associated with enhanced peripheral insulin sensitivity in adult humans and rodents (Semple et al., 2006). To our knowledge, this is the first study to report the impact of omega-3 supplementation in pregnancy on fat mass in the mother, and it will be important to determine whether this same effect is also seen in humans, particularly given the increasing number of pregnancies which are complicated by maternal overweight and obesity (Catalano, 2007).

In agreement with clinical data from human pregnancies (Makrides et al., 2006, 2010), and previous studies in animals (Korotkova et al., 2002), we found no effect of maternal omega3 supplementation on pregnancy outcomes including number of offspring and the proportion of males and females. Unlike clinical studies, which have reported that maternal omega-3 supplementation during pregnancy is associated with a $\sim 2.6$ day $(\sim 1 \%)$ increase in gestation length and small but significant increase in birth weight of $\sim 47 \mathrm{~g}(\sim 1.3 \%$ of average birth weight; Makrides 

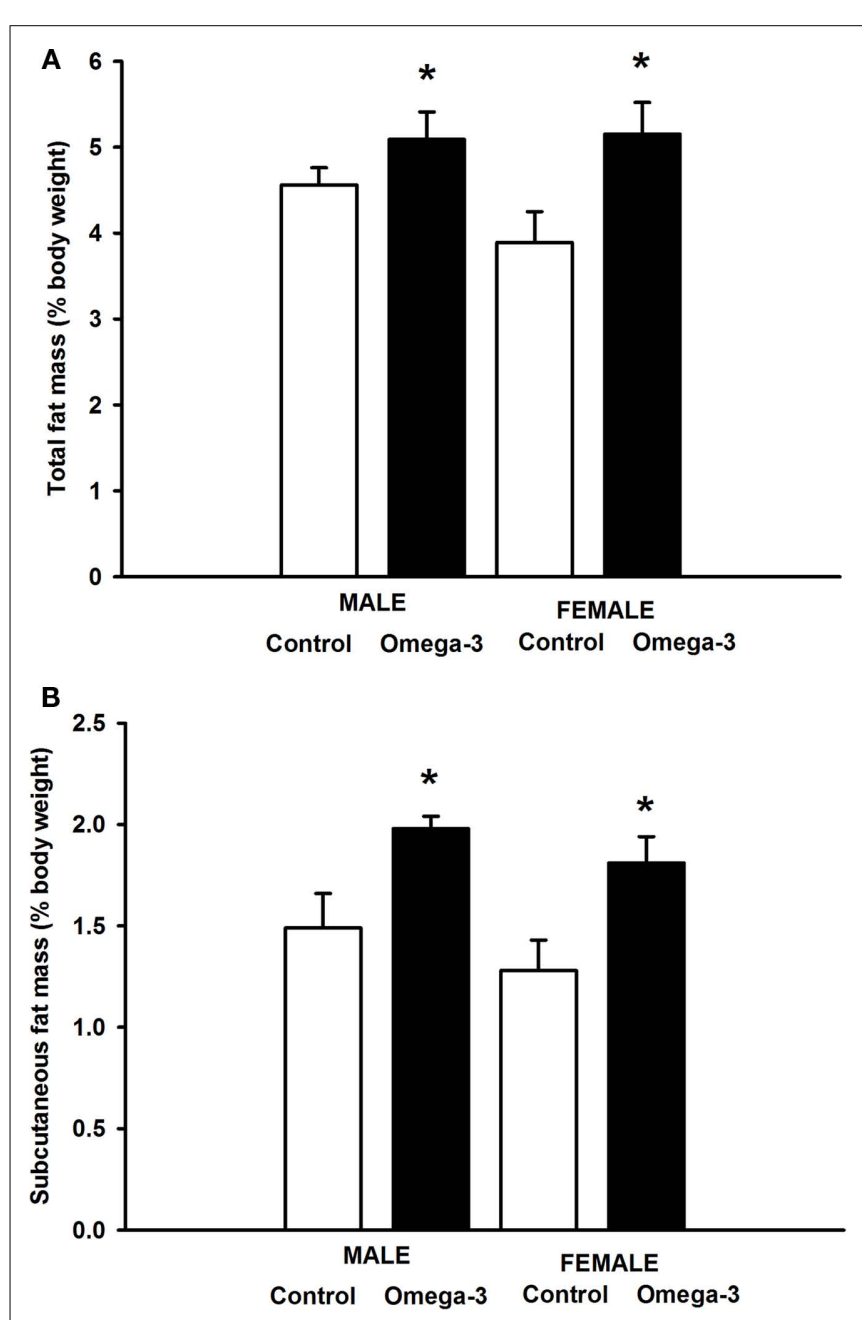

FIGURE 2 | (A) Percentage Total body fat mass and (B) Percentage subcutaneous fat mass in male and female Control (open histograms) and Omega-3 (closed histograms) offspring at 6 weeks of age. The effect of sex and treatment on body fat mass were determined by a two-way ANOVA. Asterisks indicate a significant main effect of maternal omega-3 supplementation during pregnancy and lactation $(P<0.05)$.

et al., 2006), we found no effect of maternal omega-3 supplementation on gestation length or birth weight. It is likely, however, that the relatively short gestation length of the rodent ( $\sim 21$ days) compared to the human and the lower number of animals compared to the number of infants in human clinical studies would have made it very difficult to detect such a modest increase in gestation length ( $1 \%$ of a rodent gestation would be 0.21 days). Similarly, the increased birth weight in human infants is thought to be a result of the modest increase in gestation length, and it would be unlikely that such a small increase would be detectable in a rodent model. Our findings are also in agreement with those of previous rodent studies of maternal omega- 3 supplementation, which also found no effects on birth weight (gestation length not reported; Korotkova et al., 2002; Ibrahim et al., 2009). Overall, the data from our study support previous findings that there are no significant adverse effects on the mother or on neonatal outcomes associated with maternal omega-3 supplementation in humans (Makrides et al., 2006, 2010).

It has been demonstrated in previous studies that the level of EPA and DHA in the breast milk is directly related to maternal intake (Makrides et al., 1996), and this appeared to be the case in the present study since the omega-3 pups had significantly higher EPA, DHA, and total omega-3 LCPUFA concentrations in their erythrocyte phospholipids at weaning compared to the Control group. Importantly, the elevated EPA, DHA, and total omega-3 LCPUFA concentration in erythrocyte phospholipids persisted at 6 weeks of age, at which time all offspring (in both control and omega-3 treatment groups) had been consuming a standard rat chow (not supplemented with omega-3 LCPUFA) since weaning. It therefore appears that fatty acids incorporated into erythrocyte phospholipids before or during the suckling period are retained after weaning and therefore have the potential to have more prolonged biological effects. This is perhaps not unexpected, since it has been shown that it takes about 2-3 weeks for changes in dietary fat composition to result in significant alterations in erythrocyte fatty acid composition (Lands et al., 1990, 1992).

Apart from the clear alterations in fatty acid status of the omega-3 offspring at weaning there appeared to be little effect of maternal omega-3 supplementation on growth or fat deposition during the suckling period, and there were no differences in either visceral or subcutaneous fat mass between the control and omega-3 offspring at weaning. The lack of effect of an increased omega-3 supply in early infancy on postnatal growth is consistent with data in term infants, where there is little evidence that an increased supply of EPA and DHA in either breast milk or formula during the immediate postnatal period is associated with an altered weight gain in early infancy (Makrides et al., 1999, 2005). The lower plasma NEFA concentrations in both male and female omega-3 offspring at weaning, however, suggests that there may have been an increased uptake of fatty acids into adipose tissue at the end of weaning, although further studies are required to test this hypothesis directly.

Whilst there was no difference in body weight at 6 weeks of age, we found that percentage body fat mass was significantly increased in both male and female omega- 3 offspring. This suggests that, contrary to our hypothesis, an increased supply of omega-3 LCPUFA during the major period of fat development in the rodent augmented fat accumulation and/or restricted growth of lean mass in early postnatal life. This is unexpected, given the previous data linking increased omega-3 LCPUFA with reduced fat differentiation and accumulation in adult rodents and in vitro studies (Massiera et al., 2003; Masden et al., 2005) and in offspring supplied with a high omega-3 diet in the post-weaning period (Massiera et al., 2003; Wyrwoll et al., 2006; Ibrahim et al., 2009). It is also at odds with the results of the only other study to date which has determined the effect of exposure to an increased supply of omega-3 LCPUFA during the perinatal period alone on body fat mass in the offspring later in life (Korotkova et al., 2002). However, this previous study only determined fat mass and adipocyte cell size in offspring at 1 and 3 weeks of age, and may therefore not have detected increases in fat mass which emerged later in postnatal life. With the exception of the study by Wyrwoll et al. (2006), which assessed percentage total body fat using Dual X-ray 
Table 6 | Expression of adipocyte genes in retroperitoneal and subcutaneous adipose tissue at 6 weeks of age in offspring of Control and Omega-3 dams (normalized to $\beta$-actin).

\begin{tabular}{|c|c|c|c|c|}
\hline & \multicolumn{2}{|c|}{ Male } & \multicolumn{2}{|c|}{ Female } \\
\hline & Control $(n=10)$ & Omega-3 $(n=10)$ & Control $(n=10)$ & Omega-3 $(n=10)$ \\
\hline SREBP-1c mRNA $(\times 1000)$ & $0.9 \pm 0.02$ & $1.4 \pm 0.3$ & $1.7 \pm 0.4$ & $1.8 \pm 0.5$ \\
\hline PPAR $\gamma$ mRNA & $0.0143 \pm 0.003$ & $0.0161 \pm 0.003$ & $0.0141 \pm 0.003$ & $0.0136 \pm 0.003$ \\
\hline FAS mRNA & $0.131 \pm 0.058$ & $0.152 \pm 0.039$ & $0.567 \pm 0.085^{\#}$ & $0.316 \pm 0.084^{\# \dagger}$ \\
\hline Leptin mRNA & $0.0153 \pm 0.006$ & $0.0122 \pm 0.005$ & $0.0071 \pm 0.002$ & $0.0068 \pm 0.002$ \\
\hline \multicolumn{5}{|l|}{ SUBCUTANEOUS } \\
\hline SREBP-1c mRNA & $0.0087 \pm 0.0030$ & $0.0075 \pm 0.0006$ & $0.0087 \pm 0.003$ & $0.0130 \pm 0.005$ \\
\hline PPAR $\gamma$ mRNA $(\times 1000)$ & $0.82 \pm 0.03$ & $0.67 \pm 0.02$ & $1.7 \pm 0.7$ & $0.7 \pm 0.3$ \\
\hline FAS mRNA & $0.251 \pm 0.060$ & $0.256 \pm 0.130$ & $0.353 \pm 0.170$ & $0.104 \pm 0.047$ \\
\hline G3PDH mRNA & $0.220 \pm 0.11$ & $0.221 \pm 0.089$ & $0.363 \pm 0.180$ & $0.105 \pm 0.046$ \\
\hline
\end{tabular}

All values expressed as mean \pm SEM. The effect of Omega-3 treatment and sex was determined using a two-way ANOVA. "denotes $P<0.05$ compared to male offspring; ${ }^{\dagger}$ denotes $P=0.06$ compared to Control females.

Absorptiometry, existing rodent studies have not included measures of subcutaneous fat mass, and may therefore have failed to pick up on differences in fat mass confined largely to this adipose depot.

We found no effect of maternal omega-3 supplementation on the expression of adipogenic and lipogenic genes in either the retroperitoneal or subcutaneous fat depots at 6 weeks of age, which implies that the increase in subcutaneous fat accumulation was the result of a mechanism other than the upregulation of lipogenic gene expression. It is also clear that DHA did not suppress SREBP1c expression in fat depots during the early postnatal period in the same way that it has been reported in adult rodents (Ailhaud et al., 1992). The obvious differences in the effects of omega-3 LCPUFA supplementation between adults and neonates suggest that it may not be appropriate to extrapolate data obtained in mature adipocytes to those for developing adipose cells.

So, how might an increased availability of omega-3 LCPUFA augment fat deposition in early life? One possibility may be that the increases in the availability of omega-3 LCPUFA leads to increased activation of PPAR $\gamma$ in developing adipose depots, thereby promoting fat cell differentiation (Soret et al., 1999) and precocial lipid accumulation in developing adipocytes (Hutley et al., 2003), and increasing peripheral insulin sensitivity (Semple et al., 2006). Omega-3 LCPUFA have been shown to act as PPAR $\gamma$ agonists in vivo (Deckelbaum et al., 2006; Neschen et al., 2006) and chronic treatment with synthetic PPAR $\gamma$ agonists is associated with increases in subcutaneous, but not visceral, fat mass in adults (Smith et al., 2005; Buckingham and Hanna, 2008). This is also supported by epigenetic studies which have shown that omega-3 LCPUFA inhibit the activity of the H3K27 methyltransferase, Ezh2, in cancer cells (Dimri et al., 2010). Since Ezh2 has been shown to directly repress $\mathrm{Wnt} / \beta$-catenin signaling (Wang et al., 2010) and $W n t / \beta$-catenin signaling inhibits adipogenesis, reductions in Ehz2 activity as a result of omega-3 LCPUFA supplementation would be expected to facilitate adipogenesis. The ability of omega-3 LCPUFA supplementation to induce epigenetic changes during development is clearly an important area for future investigation.

\section{CONCLUSION}

Although there has been much speculation about the potential for maternal omega-3 LCPUFA supplementation to limit fat accumulation and improve long-term metabolic health in the offspring (Ailhaud et al., 2006; Hauner et al., 2009; Muhlhausler et al., 2010a), there is still limited evidence which supports this hypothesis. In the present study, we have demonstrated that maternal omega-3 supplementation during pregnancy and lactation in a rodent model resulted in increased fat accumulation in both male and female offspring in early postnatal life. These data, together with evidence from recent clinical studies (Lauritzen et al., 2005; Asserhoj et al., 2009), suggest that the effect of omega-3 LCPUFA on pre-adipocytes and developing fat depots is likely to be distinct from their effects on mature adipose depots and cells in culture, and that there is a need to exercise caution when extrapolating results from adult and in vitro studies to effects during development in vivo. It is important to note that the increase in fat mass is restricted to subcutaneous depots, whereas the majority of adverse metabolic effects of obesity are the result of excess visceral adipose tissue (Smith et al., 2001), and therefore the metabolic health of the offspring may not necessarily be adversely affected. It is clear that further studies are required in order to more fully elucidate the mechanisms of action of omega-3 LCPUFA on fat depots, including epigenetic effects, and to determine the effects of maternal omega-3 supplementation on metabolic health of the offspring throughout the life-course

\section{ACKNOWLEDGMENTS}

This work was funded by a grant from the Division of Health Sciences, University of South Australia and a Channel 7 Children's 
Health Research Foundation grant to Beverly Sara Muhlhausler. Beverly Sara Muhlhausler is supported by a Career Development Award from the National Health and Medical Research Council of Australia (NHMRC). Robert A. Gibson is supported by

\section{REFERENCES}

Ailhaud, G., Grimaldi, P., and Negrel, R. (1992). Cellular and molecular aspects of adipose tissue development. Annu. Rev. Nutr. 12, 207-233.

Ailhaud, G., Massiera, F., Weill, P., Legrand, P., Alessandri, J. M., and Guesnet, P. (2006). Temporal changes in dietary fats: role of n-6 polyunsaturated fatty acids in excessive adipose tissue development and relationship to obesity. Prog. Lipid Res. 45, 203-236.

Armitage, J. A., Khan, I. Y., Taylor, P. D., Nathanielsz, P. W., and Poston, L. (2004). Developmental programming of the metabolic syndrome by maternal nutritional imbalance: how strong is the evidence from experimental models in mammals? J. Physiol. (Lond.) 561, 355-377.

Asserhoj, M., Nehammer, S., Matthiessen, J., Michaelsen, K. F., and Lauritzen, L. (2009). Maternal fish oil supplementation during lactation may adversely affect longterm blood pressure, energy intake, and physical activity of 7-year-old boys. J. Nutr. 139, 298-304.

Bligh, E. G., and Dyer, W. J. (1959). A rapid method of total lipid extraction and purification. Can. J. Biochem. Physiol. 37, 911-917.

Buckingham, R. E., and Hanna, A. (2008). Thiazolidinedione insulin sensitizers and the heart: a tale of two organs? Diabetes Obes. Metab. 10, 312-328.

Catalano, P. M. (2007). Management of obesity in pregnancy. Obstet. Gynecol. 109, 419-433.

Deckelbaum, R. J., Worgall, T. S., and Seo, T. (2006). n-3 fatty acids and gene expression. Am. J. Clin. Nutr. 83, 1520S-1525S.

Dimri, M., Bommi, P. V., Sahasrabuddhe, A. A., Khandekar, J. D., and Dimri, G. P. (2010). Dietary omega-3 polyunsaturated fatty acids suppress expression of EZH2 in breast cancer cells. Carcinogenesis 31, 489-495.

Hauner, H., Vollhardt, C., Schneider, K. T., Zimmermann, A., Schuster, T., and Amann-Gassner, U. (2009). The impact of nutritional fatty acids during pregnancy and lactation on early human adipose tissue development. Rationale and design of the INFAT study. Ann. Nutr. Metab. 54, 97-103.

Hutley, L. J., Newell, F. M., Joyner, J. M., Suchting, S. J., Herington, A.
C., Cameron, D. P., and Prins, J. B. (2003). Effects of rosiglitazone and linoleic acid on human preadipocyte differentiation. Eur. J. Clin. Invest. 33, 574-581.

Ibrahim, A., Null, G., Basak, S., and Ehtesham, N. Z. (2009). Impact of maternal dietary fatty acid composition on glucose and lipid metabolism in male rat offspring aged 105 d. Br. J. Nutr. 102, 233-241.

Kasser, T. R., Martin, R. J., and Allen, C. E. (1981). Effect of gestational alloxan diabetes and fasting on fetal lipogenesis and lipid deposition in pigs. Biol. Neonate 40, 105-112.

Korotkova, M., Gabrielsson, B., Lonn, M., Hanson, L.-A., and Strandvik, B. (2002). Leptin levels in rat offspring are modified by the ratio of linoleic to \{alpha\}-linolenic acid in the maternal diet. J. Lipid Res. 43, 1743-1749.

Lands, W. E., Libelt, B., Morris, A., Kramer, N. C., Prewitt, T. E., Bowen, P., Schmeisser, D., Davidson, M. H., and Burns, J. H. (1992). Maintenance of lower proportions of $(n-6)$ eicosanoid precursors in phospholipids of human plasma in response to added dietary ( $\mathrm{n}-3)$ fatty acids. Biochim. Biophys. Acta 1180, 147-162.

Lands, W. E., Morris, A., and Libelt, B. (1990). Quantitative effects of dietary polyunsaturated fats on the composition of fatty acids in rat tissues. Lipids 25, 506-516.

Lauritzen, L., Hoppe, C., Straarup, E. M., and Michaelsen, K. F. (2005). Maternal fish oil supplementation in lactation and growth during the first 2.5 years of life. Pediatr. Res. 58, 235-242.

Makrides, M., Duley, L., and Olsen, S. F. (2006). Marine oil, and other prostaglandin precursor, supplementation for pregnancy uncomplicated by pre-eclampsia or intrauterine growth restriction. Cochrane Database Syst. Rev. 3, 1-25.

Makrides, M., Gibson, R. A., McPhee, A. J., Yelland, L., Quinlivan, J., Ryan, P., and Team, D. I. (2010). Effect of DHA supplementation during pregnancy on maternal depression and neurodevelopment of young children. JAMA 304, 1675-1683.

Makrides, M., Gibson, R. A., Udell, T., Ried, K., and the International, L. I. (2005). Supplementation of infant

a Senior Research Fellowship from the NHRMC. The authors wish to acknowledge the assistance of Mr. David Phuong and Ms. Lauren Astill with assistance with animal protocols and John Carragher for assistance in editing the manuscript.

formula with long-chain polyunsaturated fatty acids does not influence the growth of term infants. Am. J. Clin. Nutr. 81, 1094-1101.

Makrides, M., Neumann, M. A., and Gibson, R.A. (1996). Effect of maternal docosahexaenoic acid (DHA) supplementation on breast milk composition. Eur. J. Clin. Nutr. 50, 352-357.

Makrides, M., Neumann, M. A., Simmer, K., and Gibson, R. A. (1999). Dietary long-chain polyunsaturated fatty acids do not influence growth of term infants: a randomized clinical trial. Pediatrics 104, 468-475

Makrides, M., Simmer, K., Neumann, M., and Gibson, R. (1995). Changes in the polyunsaturated fatty acids of breast milk from mothers of fullterm infants over $30 \mathrm{wk}$ of lactation. Am. J. Clin. Nutr. 61, 1231-1233.

Masden, L., Koefoed Petersen, R., and Kristiansen, K. (2005). Regulation of adipocyte differentiation and function by polyunsaturated fatty acids. Biochim. Biophys. Acta 1740, 266-286.

Massiera, F., Guesnet, P., and Ailhaud, G. (2006). The crucial role of dietary n-6 polyunsaturated fatty acids in excessive adipose tissue development: relationship to childhood obesity. Nestle Nutr. Workshop Ser. Pediatr. Program. 57, 235-242.

Massiera, F., Saint-Marc, P., Seydoux, J., Murata, T., Kobayashi, T., Narumiya, S., Guesnet, P., Amri, E.-Z., Negrel, R., and Ailhaud, G. (2003). Arachidonic acid and prostacyclin signaling promote adipose tissue development: a human health concern? J. Lipid Res. 44, 271-279.

McMillen, I. C., and Robinson, J. S. (2005). Developmental origins of the metabolic syndrome: prediction, plasticity, and programming. Physiol. Rev. 85, 571-633.

Meyer, B. J., Mann, N. J., Lewis, J. L., Milligan, G. C., Sinclair, A. J., and Howe, P. R. (2003). Dietary intakes and food sources of omega-6 and omega3 polyunsaturated fatty acids. Lipids 38, 391-398.

Muhlhausler, B. S., Adam, C. L., Findlay, P. A., Duffield, J. A., and McMillen, I. C. (2006). Increased maternal nutrition alters development of the appetite-regulating network in the brain. FASEB J. 20, 1257-1259.

Muhlhausler, B. S., Cook-Johnson, R., James, M., Miljkovic, D., Duthoit, E., and Gibson, R. (2010a). Opposing effects of omega-3 and omega-6 long chain polyunsaturated fatty acids on the expression of lipogenic genes in omental and retroperitoneal adipose depots in the rat. J. Nutr. Metab. doi: 10.1155/2010/927836. [Epub ahead of print].

Muhlhausler, B. S., Gibson, R. A., and Makrides, M. (2010b). Effect of long-chain polyunsaturated fatty acid supplementation during pregnancy or lactation on infant and child body composition: a systematic review. Am. J. Clin. Nutr. 92, 857-863.

Muhlhausler, B. S., Duffield, J. A., and McMillen, I. C. (2007). Increased maternal nutrition stimulates peroxisome proliferator activated receptor-\{gamma\} (PPAR \{gamma\}), adiponectin and leptin mRNA expression in adipose tissue before birth. Endocrinology 148, 878-885.

Neschen, S., Morino, K., Rossbacher, J. r. C., Pongratz, R. L., Cline, G. W., Sono, S., Gillum, M., and Shulman, G. I. (2006). Fish oil regulates adiponectin secretion by a peroxisome proliferatorâ $€$ “activated receptor-g dependent mechanism in mice. Diabetes 55, 924-928.

Okuno, M., Kajiwara, K., Imai, S., Kobayashi, T., Honma, N., Maki, T., Suruga, K., Goda, T., Takase, S., Muto, Y., and Moriwaki, H. (1997). Perilla oil prevents the excessive growth of visceral adipose tissue in rats by down-regulating adipocyte differentiation. J. Nutr. 127, 1752-1757.

Plagemann, A., Harder, T., Kohlhoff, R., Rhode, W., and Dorner, G. (1997). Overweight and obesity in infants of mothers with long-term insulindependent diabetes or gestational diabetes. Int. J. Obes. Relat. Metab. Disord. 21, 451-456.

Raclot, T., Groscolas, R., Langin, D., and Ferre, P. (1997). Site-specific regulation of gene expression by n-3 polyunsaturated fatty acids in rat white adipose tissues. J. Lipid Res. 38, 1963-1972.

Ruzickova, J., Rossmeisl, M., Prazak, T., Flachs, P., Sponarova, J., Veck, M., Tvrzicka, E., Bryhn, M., and Kopecky, J. (2004). Omega-3 PUFA of marine origin limit diet-induced obesity in mice by reducing 
cellularity of adipose tissue. Lipids 39, 1177-1185.

Semple, R. K., Chatterjee, V. K. K., and O'Rahilly, S. (2006). PPAR \{gamma\} and human metabolic disease. $J$. Clin. Invest. 116, 581-589.

Smith, S. R., de Jonge, L., Volaufova, J., Li, Y., Xie, H., and Bray, G. A. (2005). Effect of pioglitazone on body composition and energy expenditure: a randomized controlled trial. Metab. Clin. Exp. 54, 24-32.

Smith, S. R., Lovejoy, J. C., Greenway, F., Ryan, D., deJonge, L., de la Bretonne, J., Volafova, J., and Bray, G. A. (2001). Contributions of total body fat, abdominal subcutaneous adipose tissue compartments, and visceral adipose tissue to the metabolic complications of obesity. Metab. Clin. Exp. 50, 425-435.

Soret, B., Lee, H. J., Finley, E., Lee, S. C., and Vernon, R. G. (1999). Regulation of differentiation of sheep subcutaneous and abdominal preadipocytes in culture. J. Endocrinol. 161, 517524.

Wang, L., Jin, Q., Lee, J.-E., Su, I.-H., and Ge, K. (2010) Histone H3K27 methyltransferase Ezh2 represses Wnt genes to facilitate adipogenesis. Proc. Natl. Acad. Sci. U.S.A. 107, 7317-7322.

World Health Organisation. (2006). Fact Sheet: Obesity and Overweight. Available at: http://www.who. int/mediacentre/factsheets/fs $311 /$ en/ print.html., World Health Organisation.

Wyrwoll, C. S., Mark, P. J., Mori, T. A., Puddey, I. B., and Waddell, B. J. (2006). Prevention of programmed hyperleptinemia and hypertension by postnatal dietary \{omega\}-3 fatty acids. Endocrinology 147, 599-606.

Conflict of Interest Statement: The authors declare that the research was conducted in the absence of any commercial or financial relationships that could be construed as a potential conflict of interest.

Received: 10 May 2011; accepted: 05 July 2011; published online: 21 July 2011.
Citation: Muhlhausler BS, Miljkovic D, Fong L, Xian CJ, Duthoit E and Gibson RA (2011) Maternal omega-3 supplementation increases fat mass in male and female rat offspring. Front. Gene. 2:48. doi: 10.3389/fgene.2011.00048

This article was submitted to Frontiers in Epigenomics, a specialty of Frontiers in Genetics.

Copyright (ㅇ 2011 Muhlhausler, Miljkovic, Fong, Xian, Duthoit and Gibson. This is an open-access article subject to a non-exclusive license between the authors and Frontiers Media SA, which permits use, distribution and reproduction in other forums, provided the original authors and source are credited and other Frontiers conditions are complied with. 